\title{
Fran zWITTER, Les Provinces illyriennes. Cinq études, édition conçue et préparée par Alain Jejcic
}

\author{
Éric Gojosso
}

\section{(2) OpenEdition \\ Journals}

Édition électronique

URL : https://journals.openedition.org/ahrf/12260

DOI : $10.4000 /$ ahrf. 12260

ISSN : 1952-403X

Éditeur :

Armand Colin, Société des études robespierristes

Édition imprimée

Date de publication : 1 décembre 2011

Pagination : 186-188

ISSN : 0003-4436

Référence électronique

Éric Gojosso, «Fran zwITTER, Les Provinces illyriennes. Cinq études, édition conçue et préparée par Alain Jejcic ", Annales historiques de la Révolution française [En ligne], 366 | octobre-décembre 2011, mis en ligne le 13 février 2012, consulté le 01 juillet 2021. URL : http://journals.openedition.org/ahrf/12260 ; DOl : https://doi.org/10.4000/ahrf.12260

Ce document a été généré automatiquement le 1 juillet 2021.

Tous droits réservés 


\title{
Fran ZWITTER, Les Provinces illyriennes. Cinq études, édition conçue et préparée par Alain Jejcic
}

\author{
Éric Gojosso
}

\section{RÉFÉRENCE}

Fran zWITTER, Les Provinces illyriennes. Cinq études, édition conçue et préparée par Alain Jejcic, Paris, éditions SPM, 2010, 218 p., ISBN 978-2-901952-74-9, $30 €$

1 Avec le soutien de l'ambassade de Slovénie en France, Alain Jejcic a réuni dans un même livre plusieurs études sur les provinces illyriennes dues à la plume de l'historien slovène Fran Zwitter, parues entre 1931 et 1983, dont certaines n'avaient jamais été publiées en français. Celles-ci se trouvent complétées par deux notices rédigées par Janez Šumrada, l'une présentant succinctement la vie de l'auteur, l'autre cherchant à apprécier son rôle dans le développement de l'historiographie slovène de l'Illyrie napoléonienne. Enfin, l'esquisse d'un dictionnaire biographique illyrien due à Alain Jejcic et à Peter Vodopivec clôt cet intéressant volume.

2 Les travaux ici rassemblés sont traversés par une interrogation commune: que représente l'expérience napoléonienne dans l'histoire de la Yougoslavie - dont Zwitter, mort en 1988, ne pouvait pressentir l'éclatement, lui le slovène qui siégeait aux académies de Zagreb et de Belgrade? Dans cette optique, l'auteur est conduit à accorder une place centrale à la notion d'«illyrisme politique » en revenant sur les conditions intellectuelles, politiques, économiques et sociales de son émergence. L'illyrisme est, pour Zwitter, « la première forme sous laquelle apparaît dans l'histoire l'idée yougoslave » (p. 46).

3 L'enquête passe par la mise en exergue des véritables motivations ayant conduit Napoléon à créer les provinces illyriennes, assimilées par l'auteur, trop rapidement sans doute, à une formation étatique particulière. L'empereur n'a pas été mû par un 
« illyrisme politique » qu'il aurait eu à cœur d'accomplir en libérant les Slaves du Sud de la domination habsbourgeoise. La vision romantique véhiculée un temps par Vodnik doit être écartée au profit d'une approche plus réaliste. L'annexion des provinces maritimes de l'Autriche a obéi à plusieurs facteurs en lien avec la promotion des intérêts français : relier sans discontinuité territoriale l'Italie, l'Istrie et la Dalmatie; disposer d'une frontière commune avec l'Empire ottoman dans l'éventualité d'une invasion de celui-ci ; contrecarrer l'influence de la Russie sur les populations slaves de l'Adriatique ; appliquer strictement le blocus continental ; rétablir une voie terrestre pour le commerce avec le Levant. L'entourage de Napoléon et l'empereur lui-même ne semblent s'être préoccupés de la question nationale que de manière tardive, à l'heure où les négociations de paix aboutissaient (sept.-oct. 1809). Ils ne lui ont du reste jamais accordé un grand crédit, si bien que l'avènement d'un sentiment illyrien (surtout slovène et croate) n'est en définitive qu'une des conséquences involontaires de la domination napoléonienne en Adriatique orientale, du reste moins liée à la politique impériale qu'à l'idéologie révolutionnaire propagée par les Français. Le fait que cet illyrisme se soit identifié à une langue propre, déclinée en plusieurs dialectes, en dit long sur l'ambiguïté de la dette contractée, le critère étant ici plus objectif que subjectif, selon les termes du débat posés par Renan.

4 L'œuvre française se ressent des ambiguïtés initiales : elle est en demi-teinte. Les nouveaux maîtres de l'lllyrie n'ont ni immédiatement ni totalement traduit en actes les principes juridiques de la Révolution. Dans la voie des réformes, Zwitter le rappelle à bon droit, ils furent même précédés par l'Autriche, en tout cas dans la partie des provinces illyriennes naguère sous la domination des Habsbourg. Ils l'ont bien entendu dépassée, tant dans la voie de la centralisation bureaucratique que du rejet de la féodalité : les assemblées territoriales ni les seigneurs ne furent plus associés à la gestion des affaires locales. Ils ont aussi prolongé l'œuvre autrichienne en intégrant par exemple les communes fiscales de Joseph II dans des arrondissements communaux, à leur tour rassemblés dans des cantons. Ainsi comprend-on mieux pourquoi, dans ce registre, la réaction qui intervint après 1813 , ne fut pas complète : si la circonscription cantonale disparut, l'arrondissement communal fut maintenu. Bien que dans le domaine du droit et de la justice aussi il faille porter au crédit de Vienne les premières réformes, la rupture fut également sensible avec l'introduction des codes napoléoniens, l'abolition des anciens tribunaux, la suppression des privilèges nobiliaires et ecclésiastiques et l'institution de nouvelles juridictions. Janez Kranjc donne plus de détails dans son article «L'administration de la justice et les lois françaises en vigueur dans les Provinces illyriennes" publié par les Cahiers poitevins d'histoire du droit, (3e cahier 2011, p. 21-42). La législation française et ses présupposés philosophiques provoquèrent en outre des mutations économiques et sociales d'envergure auxquelles Zwitter accorde une place centrale dans ses travaux: la conception de la propriété, débarrassée en grande partie de ses vestiges féodaux, s'en trouva bouleversée, la division du sol fut admise, la liberté du travail et du commerce consacrée, la fiscalité revue et abaissée...

5 Les réalisations françaises prêtent naturellement le flanc à la critique, mais il est erroné de les décrire comme foncièrement inadaptées à la réalité illyrienne et par là même vouées à l'échec, comme l'a fait Bogumil Vosnjak. L'exemple de l'organisation territoriale en témoigne. Les découpages adoptés (en intendances ou en provinces civiles et militaire) ne furent pas fonction de seules considérations géographiques. Le passé aussi fut pris en compte - plus encore qu'il ne l'avait été en France à l'époque de 
la Constituante. Sans doute les réformes napoléoniennes étaient-elles davantage compatibles avec les structures juridiques et sociales de la Carniole que de la Croatie. Elles ne furent pas toutefois sans portée, au delà même de la période napoléonienne dont il ne faut pas perdre de vue la brièveté : 1809-1813. Encore ce créneau mériterait-il d'être reconsidéré du point de vue de son terminus a quo. Ainsi que l'a fort bien marqué Janez Šumrada, dans l'ouvrage qu'il a codirigé sur Napoléon et son administration en Adriatique orientale et dans les Alpes de l'Est, 1806-1814, l'introduction des institutions françaises, par-delà le régime provisoire, intervint seulement en 1811, l'empereur ayant obtenu la main de Marie-Louise sans avoir à restituer à l'Autriche ses provinces maritimes, hypothèque capitale qui avait grevé toute action pendant près de dix-huit mois. À ce sujet, il faut voir le compte-rendu que nous avons fait dans le no 4-2006 de la RHDFE (p. 649-651). Dans un laps de temps si court, 1811-1813, la transposition complète du système français était impossible.

Le recueil publié à l'initiative d'Alain Jejcic est à mettre en perspective avec le catalogue de l'exposition consacrée au bicentenaire des provinces illyriennes (Pod Napoleonovim Orlom / Sous les aigles napoléoniennes, Narodni Muzej Slovenije, 2010, 452 pages, 39 euros) dans lequel on trouvera une série de notices synthétiques sur la création de cet ensemble territorial, sa perception par les Slovènes et différents aspects de la vie locale à cette époque. 